\title{
Early Postoperative Anticoagulation by Enoxaparin after Mechanical Aortic Valve Replacement
}

\author{
Younes Moutakiallah, Mehdi Bamous, Roland Henaine, Jacques Robin, \\ Jean François Obadia, Jean Ninet \\ Department of Cardiac Surgery, C. Louis Pradel Cardiologic Hospital, Lyon, France \\ Email: dryouns@hotmail.com
}

Received 15 May 2014; revised 15 June 2014; accepted 25 July 2014

Copyright (C) 2014 by authors and Scientific Research Publishing Inc.

This work is licensed under the Creative Commons Attribution International License (CC BY).

http://creativecommons.org/licenses/by/4.0/

cC) (i) Open Access

\begin{abstract}
Background: The use of low molecular weight heparin for early anticoagulation after mechanical aortic valve replacement is still a matter of debate even more that the early postoperative phase is associated with maximum of thrombo-embolic and bleeding risks. The objective of this study is to verify the efficacy and the safety of low molecular weight heparin for the early anticoagulation after mechanical aortic valve replacement. Methods and Results: It is a prospective study conducted over 6 months and interested 40 consecutive patients ( 32 male and 8 female) with a mean age $53.83 \pm 16.93$ years (19 - 75 years) who underwent a mechanical aortic valve replacement and received enoxaparin as bridging therapy between continuous unfractionated heparin and fully effective vitamin $\mathrm{K}$ antagonist therapy. There was no in-hospital death and no in-hospital thromboembolic events. We report 2 major bleeding events (5\%). Conclusion: The use of low molecular weight heparin should be an alternative to explore for early anticoagulation after valve heart surgery and the results of our study must be verified by large randomized studies before drawing any hasty conclusions.
\end{abstract}

\section{Keywords}

Early Anticoagulation, Mechanical Aortic Valve Replacement, Low Molecular Weight Heparin

\section{Introduction}

The postoperative phase of Mechanical Valve Heart Replacement (MVHR) is associated with maximal thromboembolic (TE) and bleeding risks and optimal early anticoagulation strategy remains controversial despite pub- 
lished guidelines [1]-[4]. Although the successfully use of Low Molecular Weight Heparin (LMWH) in the treatment of many cardiovascular disease: pulmonary embolism, acute coronary syndrome, atrial fibrillation and acute myocardial infarction, the LMWH still not yet routinely used for the early anticoagulation after MVHR. The three most commonly prescribed LMWH are enoxaparin (Lovenox), dalteparin (Fragmin) and tinzaparin (Innohep) of which enoxaparin is most commonly used in clinical practice. Enoxaparin sodium is obtained by alkaline depolymerization of heparin benzyl ester derived from porcine intestinal mucosa. The drug substance is the sodium salt. The average molecular weight is about 4500 daltons.

\section{Objectives}

The aim of the study was to evaluate efficacy and safety of LMWH as bridge between immediate postoperative Unfractioned Heparin (UH) and effective Vitamin K Antagonist (VKA) therapy, using the rate of TE and bleeding events as primary endpoint during the early postoperative phase after Mechanical Aortic Valve Replacement (MAVR).

\section{Patients and Methods}

Methodology: It's a prospective study approved by our institution's Ethics Committee and conducted over 6 months in the department of cardiac surgery. It concerned 40 consecutive patients who underwent MAVR and treated by enoxaparin (Lovenox, Rhone-Poulenc-Rorer, France). All patients who underwent a MAVR were included in the study and patients with following characteristics were excluded: previous or simultaneous mitral and/or tricuspid valve surgery, renal failure (creatinin clearance $<30 \mathrm{ml} / \mathrm{mn}$ ) and previous heparin-induced thrombocytopenia. Results are expressed as mean \pm SD.

Study protocol: In postoperative period, intravenous UH was started on the 6th postoperative hour in the surgical intensive care unit. After transfer to the ward, UH was stopped and replaced by enoxaparin 2000, 4000 or 6000IU/12 hour respectively if the patient weight is less than $51 \mathrm{Kg}$, between 51 and $80 \mathrm{Kg}$ or more than $80 \mathrm{Kg}$. The anti Xa activity was measured for all patients $4 \mathrm{~h}$ after the 1st and the 3rd injection of enoxaparin for a therapeutic range between 0.10 and $0.5 \mathrm{IU} / \mathrm{ml}$. Fluindion (Previscan, Merk serono, France) was started after removal of chest drains and enoxaparin was continued until the international ratio (INR) is more than 2 (INR target $=2$ - 3). Platelet aggregations inhibitors were not systematically used, but reserved to patients who had previous or concomitant coronary artery bypass graft (CABG).

Patient population: There were 40 patients (32 male and 8 female) with a mean age of $53.83 \pm 16.93$ years (19 - 75 years). The patients had at mean $1.29 \pm 1.10(0-5)$ cardiovascular risk factors. The average weight of patients was $74.71 \pm 17.29 \mathrm{Kg}(47-115 \mathrm{Kg}) .6$ patients (15\%) was receiving in pre-operatory VKA therapy for atrial fibrillation in 3 cases (7.5\%), previous MAVR in 2 cases (5\%) and pulmonary embolism in one case (2.5\%). One patient was receiving aspirin (2.5\%) for previous CABG. Transthoracic echocardiography showed that 6 patients (15\%) had a left atrium diameter more than $45 \mathrm{~mm}$ and 4 patients (10\%) had a left ventricular ejection fraction less than $45 \%$ (Table 1 ).

Statistics: Statistical analysis was performed using the statistical software package of social science (SPSS 11.5, Chicago, Illinois, USA). All data were expressed as mean \pm standard deviation, median or prevalence as appropriate.

\section{Results}

Operative details: All operations were performed by sternotomy and all patients received $3 \mathrm{mg} / \mathrm{kg}$ of heparin to achieve an activated clotting time $>400$ seconds. Cardio-pulmonary bypass was established by aortic and atriocaval cannulation, the aorta clamped with cold intermittent antegrade cardioplegia and hypothermia at $32^{\circ} \mathrm{C}$ (Table 2). 23 patients (57.5\%) underwent simple aortic valve replacement using SJM, ATS, and Sorin prosthesis respectively in 17 (42.5\%), 4 (10\%), and 2 patients (5\%). 17 patients (42.5\%) underwent Bentall procedure using ATS valve Dacron graft for aortic root aneurysm and for type I aortic dissection respectively in 12 (30\%) and 5 patients (12.5\%). As associated procedures, one patient (2.5\%) had epicor for surgical ablation of atrial fibrillation and one patient had resection of subaortic stenosis (Table 2). The return of patients to ward was on average of 37.2 hour (1 - 10 day) and 90\% of patients returned between D1 and D2.

Anticoagulation protocol: VKA therapy (fluindion) in combination with heparin was started after removal of 
Table 1. Clinical parameters of the population.

\begin{tabular}{|c|c|c|}
\hline Parameter & Number & Percentage \\
\hline Age (years): & $53.83 \pm 16.93(19-75)$ & \\
\hline \multicolumn{3}{|l|}{ Sex: } \\
\hline Male: & 32 & $80 \%$ \\
\hline Female: & 8 & $20 \%$ \\
\hline Weight (Kg): & $74.71 \pm 17.29(47-115)$ & \\
\hline $50 \mathrm{Kg}$ and less: & 2 & $5 \%$ \\
\hline Between 51 and $80 \mathrm{Kg}$ : & 27 & $67.5 \%$ \\
\hline $81 \mathrm{Kg}$ and more: & 11 & $27.5 \%$ \\
\hline Cardiovascular risk factors: & $1.29 \pm 1.10(0-5)$ & \\
\hline Arterial hypertension: & 15 & $37.5 \%$ \\
\hline Diabetes: & 3 & $7.5 \%$ \\
\hline Smoking: & 5 & $12.5 \%$ \\
\hline Dyslipidaemia: & 4 & $10 \%$ \\
\hline Obesity: & 16 & $40 \%$ \\
\hline Preoperative VKA therapy: & 6 & $15 \%$ \\
\hline Atrial fibrillation: & 3 & $7.5 \%$ \\
\hline Previous MAVR: & 2 & $5 \%$ \\
\hline Deep venous thrombosis: & 1 & $2.5 \%$ \\
\hline \multicolumn{3}{|l|}{ Risk factors of thromboembolism: } \\
\hline Age $>60$ years & 19 & $47.5 \%$ \\
\hline Enlarged LA (diameter $>45 \mathrm{~mm}$ ) & 6 & $15 \%$ \\
\hline LVEF $<45 \%$ & 4 & $10 \%$ \\
\hline
\end{tabular}

MAVR: mechanical aortic valve replacement; VKA: Vitamin K Antagonist; LVEF: Left ventricular ejection fraction; LA: left atrium.

Table 2. Operative parameters.

\begin{tabular}{ccc}
\hline Parameter & Number & Percentage \\
\hline Procedures: & & \\
Simple MAVR: & 23 & $57.5 \%$ \\
Bentall: & 17 & $42.5 \%$ \\
Prosthesis: & 17 & \\
SJM: & 4 & $42.5 \%$ \\
ATS: & 2 & $10 \%$ \\
Sorin: & 17 & $5 \%$ \\
ATS valve Dacron graft: & \multicolumn{2}{c}{} \\
Associated procedures: & 6 & $15 \%$ \\
Coronary artery bypass graft: & 1 & $2.5 \%$ \\
Epicor: & 1 & $2.5 \%$ \\
Cure of subaortic stenosis: & & \\
\hline
\end{tabular}

MAVR: mechanical aortic valve replacement. 
chest drains and enoxaparin was continued until the target INR was superior than 2. The therapeutic range of INR was between 2 and 3. The bridging therapy with both VKA and enoxaparin lasted on average of $4.40 \pm 1.69$ day (3 - 10 day) and in $67.5 \%$ of cases the bridge lasted at least at the 4th day. The average of anti Xa activity was $0.32 \pm 0.08 \mathrm{IU} / \mathrm{ml}(0.12-0.5 \mathrm{IU} / \mathrm{ml})$ and all patients were in the therapeutic range $(0.10-0.5 \mathrm{IU} / \mathrm{ml})$ at the 1 st day after the $1^{\text {st }}$ injection and the maintained in the therapeutic range after the 3rd injection. 6 patients (15\%) received Platelet aggregations inhibitors for CABG.

Postoperative characteristics: As per the guidelines for reporting morbidity and mortality after valve heart operations, thrombo-embolism was defined as an embolic event that occurred in the absence of infection, after the immediate operative period, and a bleeding event was defined as an episode of major internal or external bleeding that caused death, permanent injury, or required transfusion [5] [6].

There was no in-hospital mortality and no TE event. However, we report two major bleeding events (5\%): 2 cases of reoperation for tamponade with a good outcome. The 1st patient was operated at 12th day for redo aortic stenosis with change of aortic prosthesis and CABG, he received aspirin, enoxaparin $4000 \mathrm{UI} / 12 \mathrm{~h}$, fluindion, and a nonsteroidal anti-inflammatory drug for chest pain; and the 2nd patient was operated for aortic stenosis by MAVR and he received enoxaparin $4000 \mathrm{UI} / 12 \mathrm{~h}$ and aspirin for previous CABG. Transthoracic echocardiography control showed also a case of non-compressive and resolving pericardial effusion (2.5\%) (Table 3).

\section{Discussion}

Thrombo-embolic events and bleeding still account for $75 \%$ of all complications of heart valve surgery. They usually occur during the first 6 months after surgery and can affect mortality and quality of life. Several postoperative ultrasound studies demonstrated the presence of non-obstructive thromboses in about $10 \%$ of cases [7]-[9]. The propensity to early thrombus formation can be attributed to difficulties of ensuring during the initial postoperative period effective anticoagulant treatment [10] [11]. Early anticoagulation after cardiac surgery remains a controversial issue, especially in terms of intensity and timing of anticoagulation.

MAVR remains the gold standard of the surgical treatment of aortic stenosis or regurgitation especially for young patient with excellent long term results thanks to technical improvement of new generation of mechanical valve prosthesis allowing better blood flow, less stasis and made of less thrombogenic material. Despite this progress, thromboembolism and bleeding remains the most frequent complication.

LMWH has several potential advantages: better safety profile with less frequent thrombocytopenia and bleeding and less osteoporosis during chronic therapy, more predictable and more rapid anticoagulant effect, and the possibility of self-administration without daily laboratory monitoring. LMWH has been used successfully in the treatment and prevention of deep vein thrombosis and pulmonary embolism; and in the treatment of unstable angina [12] and acute coronary syndrome and, more recently, acute myocardial infarction [13] [14] and atrial

Table 3. Postoperative parameters.

\begin{tabular}{lcc}
\hline Parameter & Number & Percentage \\
\hline Day of return to ward: & & \\
Mean (day): & $1.55 \pm 1.53(1-10)$ & $90 \%$ \\
D1 - D2: & 36 & \\
Anti Xa activity factor (IU/ml): & $0.32 \pm 0.08(0.12-0.5)$ & \\
Time of bridging therapy: & $4.40 \pm 1.69(3-10)$ & $67.5 \%$ \\
Mean (day): & 27 & $5 \%$ \\
2 - 4 days: & & $2.5 \%$ \\
Complications: & 1 & $0 \%$ \\
Tamponnade: & 0 & \\
Non compressive pericardial effusion: & & \\
Death: & & \\
\hline
\end{tabular}


fibrillation [15]. The benefit-risk balance of LMWH is at least as good as that of UH. Lucas et al. concluded that enoxaparin as bridge to oral anticoagulation in patients undergoing electrical cardioversion for reduction of atrial fibrillation was safer and more effective than UH and the therapeutic zone was reached more rapidly. After successful cardioversion, no cases of intracardiac thrombosis or TE events were reported in the enoxaparin group [16]. Similar findings were reported by C. Schmidt-Lucke et al., indicating that the therapeutic range of anti-Xa activity ensuring effective anticoagulation was reached during the first 24 hours after the 1st injection in $90 \%$ of patients [17].

The bioavailability and predictability of UH anticoagulation are poor. In the ESSENCE study [18] and TIMI 9B study [19], in about 50\% of patients receiving intravenous UH, effective anticoagulation was achieved on day 3. Hull et al. [20], using subcutaneous UH, observed that the target Activated Partial Thromboplastin Time (APTT) was achieved on day 2 in only 37\% of patients with recent deep vein thrombosis, despite an additional intravenous bolus of $5000 \mathrm{IU}$ of heparin. UH has not been shown to be superior to other bridging anticoagulant regimens in patients who have recently undergone MHVR [21].

In patients with a MHVR and requiring suspension of VKA for non-cardiac surgery, Kovacs and Douketis in two separate prospective studies including a total of 327 patients with MHVR treated by LMWH [22] [23], concluded that a standardized periprocedural LMWH treatment is associated with a low risk of TE events or major bleeding complications.

During the early period after MHVR; when patients normally receive both heparin and VKA until a target INR was achieved, only 2 retrospective studies with a total of 131 patients receiving LMWH have been published [24] [25] and they suggested that the therapeutic zone was achieved more rapidly and more reliably with LMWH than with UH [24] and that LMWH was at least as effective and as safe as UH [24] [25].

Montalescot [24] compared the therapeutic efficacy of LMWH and UH during the immediate postoperative period in which patients who underwent single or double MHVR received subcutaneous UH in the 1st study phase $(\mathrm{n}=106)$ and LMWH in the 2nd phase $(\mathrm{n}=102)$ (106 aortic valve replacement, 102 mitral valve replacement). The therapeutic zone was achieved very rapidly on the 2nd day for $87 \%$ of patients with LMWH (anti-Xa factor activity within the therapeutic range 0.5 to $1 \mathrm{IU} / \mathrm{mL}$ ) versus $9 \%$ of patients with UH (APTT within the therapeutic range 1.5 to 2.5 times control) and was maintained 2 weeks for $81 \%$ of patients with LMWH versus only $21 \%$ of patients with UH. This laboratory efficacy was accompanied by a similar safety and clinical efficacy with one bleeding complication in each group and one stroke in UH group. However, follow-up was short (14 days), and the number of Mitral valve replacement was low $(n=10)$ [24]. Fanikos [25] compared 29 patients receiving LMWH with 34 control patients receiving UH. After 90 days follow-up, the number of events (deaths, TE and bleeding events) was slightly but not significantly lower in the LMWH group (4 vs 9 cases) and the hospital stay was shorter and the postoperative cost was lower in LMWH group [25].

In our study; all patients were in the therapeutic range of anti Xa activity at the first day and the two major bleeding events was occurred in patients having previous cardiac surgery and receiving in addition at enoxaparin and VKA; aspirin and Non-Steroidal Anti-inflammatory Drug. In addition there was no TE event and no prosthesis thrombosis at the transthoracic echocardiography control.

Study Limitations: Our study is small and did not include a control group, we cannot comment on efficacy or safety of early LMWH after MAVR. However, as our knowledge, no randomized study evaluating LMWH early after MAVR have been conducted more than 15 years after LMWH first became available.

There are no personal conflicts of interest directly or indirectly with any commercial product or associations.

\section{Conclusion}

LMWH as bridging therapy between immediate postoperative UH and complete efficacy of oral anticoagulant appears to be an attractive option for the prevention of TE events in patients recently undergoing MAVR. These results need to be confirmed by a randomized study comparing LMWH and UH in this indication. This study must be completed by complementary neurological investigations to detect possible subclinical TE complications.

\section{Disclosures}

All the authors had participated to the patient's management and the data collect; and had corrected the manuscript. All authors declare that there is no conflict of interest in this study. 


\section{References}

[1] Mok, C.K., Boey, J., Wang, R., Chan, T.K., Cheung, K.L., Lee, P.K., Chow, J., Ng, R.P. and Tse, T.F. (1985) Warfarin versus Dipyridamole-Aspirin and Pentoxifylline-Aspirin for the Prevention of Prosthetic Heart Valve Thromboembolism: A Prospective Randomized Clinical Trial. Circulation, 72, 1059-1063. http://dx.doi.org/10.1161/01.CIR.72.5.1059

[2] Cannegieter, S.C., Rosendaal, F.R. and Briet, E. (1994) Thrombo-Embolic and Bleeding Complications in Patients with Mechanical Heart Valve Prostheses. Circulation, 89, 635-641. http://dx.doi.org/10.1161/01.CIR.89.2.635

[3] Saour, J.N., Sieck, J.O., Mamo, L.A. and Gallus, A.S. (1990) Trial of Different Intensities Of Anticoagulation in Patients with Prosthetic Heart Valves. The New England Journal of Medicine, 322, 428-432. http://dx.doi.org/10.1056/NEJM199002153220703

[4] Hirsh, J., Dalen, E., Anderson, D.R., Poller, L., Bussey, H., Ansell, J., Deykin, D. and Brandt, J.T. (1998) Oral Anticoagulants: Mechanism of Action, Clinical Effectiveness, and Optimal Therapeutic Range. Chest, 114, 445S-469S. http://dx.doi.org/10.1378/chest.114.5_Supplement.445S

[5] Edmunds Jr., L.H., Clark, R.E., Cohn, L.H., Grunkemeier, G.L., Miller, D.C. and Weisel, R.D. (1996) Guidelines for Reporting Morbidity and Mortality after Cardiac Valvular Operations. The Journal of Thoracic and Cardiovascular Surgery, 112, 708-711. http://dx.doi.org/10.1016/S0022-5223(96)70055-7

[6] Kulik, A., Rubens, F.D., Wells, P.S., Kearon, C., Mesana, T.G., Van Berkom, J. and Lam, B.K. (2006) Early Postoperative Anticoagulation After Mechanical Valve Replacement: A Systematic Review. The Annals of Thoracic Surgery, 81, 770-781. http://dx.doi.org/10.1016/j.athoracsur.2005.07.023

[7] Laffort, P., Roudaut, R., Roques, X., Lafitte, S., Deville, C., Bonnet, J. and Baudet, E. (2000) Early and Long Term (One-Year) Effects of the Association of Aspirin and Oral Anticoagulant on Thrombi and Morbidity after Replacement of the Mitral Valve with the St. Jude Medical Prosthesis: A Clinical and Transesophageal Echocardiographic Study. Journal of the American College of Cardiology, 35, 739-746. http://dx.doi.org/10.1016/S0735-1097(99)00598-7

[8] Ionescu, A., Payne, N., Fraser, G., Giddings, J., Grunkemeier, L. and Butchart, E.G. (2003) Incidence of Embolism and Paravalvular Leak after St Jude Silzone Valve Implantation: Experience from the Cardiff Embolic Risk Factor Study. Heart, 89, 1055-1061. http://dx.doi.org/10.1136/heart.89.9.1055

[9] Iung, B., Cormier, B., Dadez, E., Drissi, M.F., Tsezana, R., Viqiuer, E., Caviezel, B., Michel, P.L., Samama, M. and Vahanian, A. (1993) Small Abnormal Echos after Mitral Valve Replacement with Bileaflet Mechanical Prostheses: Predisposing Factors and Effect on Thromboembolism. The Journal of Heart Valve Disease, 2, 259-266.

[10] Butchart, E.G., Lewis, P.A., Bethel, J.A. and Breckenridge, I.M. (1991) Adjusting Anticoagulation to Prosthesis Thrombogenicity and Patient Risk Factors. Recommendations for the Medtronic Hall Valve. Circulation, 84, III61-III69.

[11] Heras, M., Chesebro, J.H., Fuster, V., Penny, W.J., Grill, D.E., Bailey, K.R., Danielson, G.K., Orszulak, T.A., Pluth, J.R., Puga, F.J., Schaff, H.V. and Larsonkeller, J.J. (1995) High risk of Thromboemboli Early after Bioprosthetic Cardiac Valve Replacement. Journal of the American College of Cardiology, 25, 1111-1119. http://dx.doi.org/10.1016/0735-1097(94)00563-6

[12] Weitz, J.I. (1997) Low Molecular Weight Heparins. The New England Journal of Medicine, 337, 688-698. http://dx.doi.org/10.1056/NEJM199709043371007

[13] Wallentin, L., Goldstein, P., Armstrong, P.W., Granger, C.B., Adgey, A.A.J., Arntz, H.R., Bogaerts, K., Danays, T., Lindahl, B., Makijarvi, M., Verheugt, F. and Van de Werf, F. (2003) Efficacy and Safety of Tenecteplase in Combination with the Low Molecular Weight Heparin Enoxaparin or Unfractionated Heparin in the Prehospital Setting: The Assessment of the Safety and Efficacy of a New Thrombolytic Regimen (ASSENT)-3 PLUS Randomized Trial in Acute Myocardial Infarction. Circulation, 108, 135-142. http://dx.doi.org/10.1161/01.CIR.0000081659.72985.A8

[14] Petersen, J.L., Mahaffey, K.W., Hasselblad, V., Antman, E., Cohen, M., Goodman, S.G., Langer, A., Blazing, M.A., Le-Moigne-Amrani, A., De Lemos, J.A., Nessel, C.C., Harrington, R.A., Ferguson, J.J., Branwald, E. and Califf, R.M. (2004) Efficacy and Bleeding Complications among Patients Randomized to Enoxaparin or Unfractionated Heparin for Antithrombin Therapy in Non ST Segment Elevation Acute Coronary Syndromes: A Systematic Overview. JAMA, 292, 89-96. http://dx.doi.org/10.1001/jama.292.1.89

[15] Stellbrink, C., Nixdorff, U., Hofmann, T., Lehmacher, W., Daniel, W.G., Hanrath, P., Geller, C., Mügge, A., Sehnert, W., Schmidt-Lucke, C. and Schmidt-Lucke, J.A. (2004) Safety and Efficacy of Enoxaparin Compared with Unfractionated Heparin and Oral Anticoagulants for Prevention of Thromboembolic Complications in Cardioversion of Non Valvular Atrial Fibrillation: The Anticoagulation in Cardioversion Using Enoxaparin (ACE) Trial. Circulation, 109, 997-1003. http://dx.doi.org/10.1161/01.CIR.0000120509.64740.DC

[16] De Luca, I., Sorino, M., De Luca, L., Colonna, P., Del Salvatore, B. and Corlianò, L. (2005) Pre and Post-Cardioversion Transesophageal Echocardiography for Brief Anticoagulation Therapy with Enoxaparin in Atrial Fibrillation Patients: A Prospective Study with a 1-Year Follow-Up. International Journal of Cardiology, 102, 447-454. http://dx.doi.org/10.1016/j.ijcard.2004.05.052 
[17] Schmidt-Lucke, C., Paar, W.D., Stellbrink, C., Nixdorff, U., Hofmann, T., Meurer, J., Grewe, R., Daniel, W.G., Hanrath, P., Mügge, A., Klein, H.U. and Schmidt-Lucke, J.A. (2007) Quality of Anticoagulation with Unfractionated Heparin Plus Phenorocoumon for the Prevention of Thromboembolic Complications in Cardioversion for Non-Valvular Atrial Fibrillation. Sub-Analysis from the Anticoagulation in Cardioversion Using Enoxaparin (ACE) Trial. Thrombosis Research, 119, 27-34. http://dx.doi.org/10.1016/j.thromres.2005.11.016

[18] Cohen, M., Demers, C., Gurfinkel, E.P., Turpie, A.G., Fromell, G., Goodman, S., Laanger, A., Califf, R., Fox, K.A., Premmereur, J. and Bigonzi, F. (1997) A Comparison of Low Molecular Weight Heparin with Unfractionated Heparin for Unstable Coronary Artery Disease: Efficacy and Safety of Subcutaneous Enoxaparin in Non-Q-Wave Coronary Events Study Group. The New England Journal of Medicine, 337, 447-452. http://dx.doi.org/10.1056/NEJM199708143370702

[19] Antman, E.M. (1996) Hirudin in Acute Myocardial Infarction: Thrombolysis and Thrombin Inhibition in Myocardial Infarction (TIMI) 9B Trial. Circulation, 94, 911-921. http://dx.doi.org/10.1161/01.CIR.94.5.911

[20] Hull, R.D., Raskob, G.E., Hirsh, J., Jay, R.M., Leclerc, J.R., Geerts, W.H., Rosenbloom, D., Sackett, D.L., Anderson, C., Harrison, L. and Gent, M. (1986) Continuous Intravenous Heparin Compared with Subcutaneous Heparin in the Initial Treatment of Proximal Vein Thrombosis. The New England Journal of Medicine, 315, 1109-1114. http://dx.doi.org/10.1056/NEJM198610303151801

[21] Schlitt, A., Buerke, M., Hauroeder, B., Peetz, D., Hundt, F., Bickel, C., Schaefer, I., Meyer, J. and Rupprecht, H.J. (2003) Fondaparinux and Enoxaparin in Comparison to Unfractionated Heparin in Preventing Thrombus Formation on Mechanical Heart Valves in an Ex-Vivo Rabbit Model. Thrombosis and Haemostasis, 90, 245-251.

[22] Kovacs, M.J., Kearon, C., Rodger, M., Anderson, D.R., Turpie, A.G.G., Bates, S.M., Desjardins, L., Douketis, J., Kahn, S.R., Solymoss, S. and Wells, P.S. (2004) Single-Arm Study of Bridging Therapy with Low-Molecular-Weight Heparin for Patients at Risk of Arterial Embolism Who Require Temporary Interruption of Warfarin. Circulation, 110, 1658-1663. http://dx.doi.org/10.1161/01.CIR.0000142859.77578.C9

[23] Douketis, J.D., Johnson, J.A., Alexander, G. and Turpie, A.G. (2004) Low Molecular Weight Heparin as Bridging Anticoagulation during Interruption of Warfarin: Assessment of a Standardized Periprocedural Anticoagulation Regimen. Archives of Internal Medicine, 164, 1319-1326. http://dx.doi.org/10.1001/archinte.164.12.1319

[24] Montalescot, G., Polle, V., Collet, J.P., Leprince, P., Bellanger, A., Gandjbakhch, I. and Thomas, D. (2000) Low Molecular Weight Heparin after Mechanical Heart Valve Replacement. Circulation, 101, 1083-1086. http://dx.doi.org/10.1161/01.CIR.101.10.1083

[25] Fanikos, J., Tsilimingras, K., Kucher, N., Rosen, A., Hieblinger, M. and Goldhaber, S. (2004) Comparison of Efficacy, Safety, and Cost of Low Molecular Weight Heparin with Continuous Infusion Unfractionated Heparin for Initiation of Anticoagulation after Mechanical Prosthetic Valve Implantation. American Journal of Cardiology, 93, 247-250. http://dx.doi.org/10.1016/j.amjcard.2003.09.054

\section{Abbreviations}

MVHR: Mechanical Valve Heart Replacement

TE: Thrombo-Embolic

LMWH: Low Molecular Weight Heparin

UH: Unfractioned Heparin

VKA: Vitamin K Antagonist

INR: International Ratio

CABG: Coronary Artery Bypass Graft

LVEF: Left Ventricular Ejection Fraction

LA: Left Atrium 
Scientific Research Publishing (SCIRP) is one of the largest Open Access journal publishers. It is currently publishing more than 200 open access, online, peer-reviewed journals covering a wide range of academic disciplines. SCIRP serves the worldwide academic communities and contributes to the progress and application of science with its publication.

Other selected journals from SCIRP are listed as below. Submit your manuscript to us via either submit@scirp.org or Online Submission Portal.
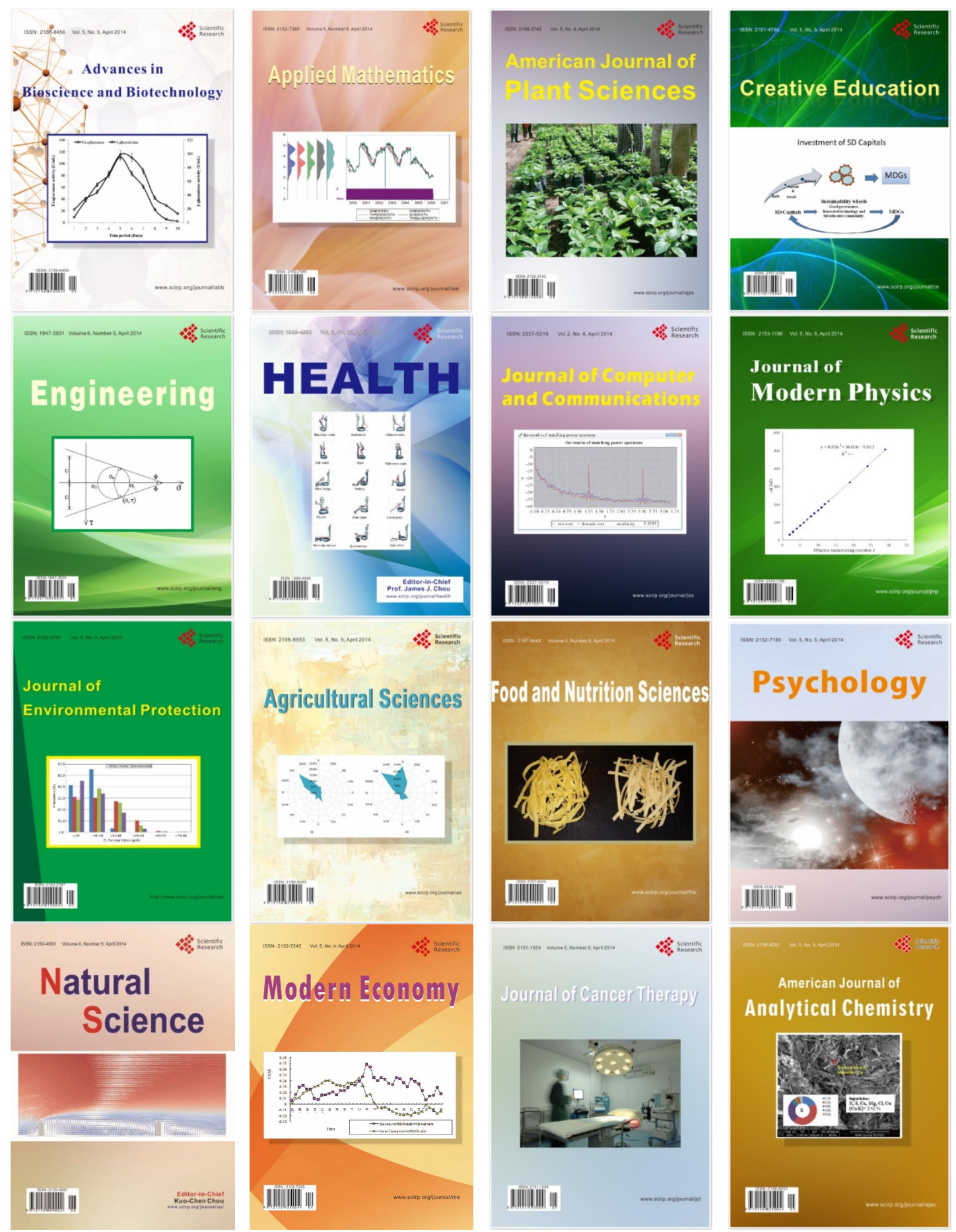